\section{In Vitro Antimicrobial Activity of an Experimental Dentifrice Based on Ricinus Communis}

Vanessa Maria Fagundes Leite ${ }^{1}$, Juliana Barchelli Pinheiro ${ }^{1}$, Marina Xavier Pisani', Evandro Watanabe ${ }^{2}$, Raphael Freitas de Souza1, Helena de Freitas Oliveira Paranhos ${ }^{1}$, Cláudia Helena Lovato-Silva ${ }^{1}$
'Department of Dental Materials and Prosthesis, School of Dentistry of Ribeirão Preto, USP - University of São Paulo, Ribeirão Preto, SP, Brazil ${ }^{2}$ Department of Restorative Dentistry, USP - University of São Paulo, School of Dentistry of Ribeirão Preto, USP - University of São Paulo, Ribeirão Preto, SP, Brazil

Correspondence: Profa. Dra. Claudia Helena Lovato da Silva, Avenida do Café, S/N, 14040-904 Ribeirão Preto, SP, Brasil. Tel: +55-16+36024006. e-mail: chl@forp.usp.br

Key words: complete denture, hygiene, dentifrice, Ricinus communis, microbiology.

\section{Introduction}

In contrast with continuous advances in dentistry and the advent of new materials and techniques, the oral health of denture wearers is still deficient. Approximately $11-65 \%$ of denture wearers are affected by denture stomatitis, a disease characterized by inflammation of the palatal mucosa. This is a multifactorial disease, however poor denture hygiene is considered to be particularly significant (1).

Inadequate denture hygiene habits lead to biofilm accumulation on the surfaces of removable dentures. Studies have shown that different species of microorganisms are associated with denture plaque. Among the bacteria, the following can be cited: Staphylococcus aureus, Streptococcus mutans, Escherichia coli, Bacillus subtilis and Pseudomonas aeruginosa (2). Candida albicans and Candida glabrata are commonly found yeast in denture biofilm and are the main etiological factors for atrophic chronic candidiasis (1). The proper cleaning of the prosthesis is vital for biofilm control and for the prevention of inflammation and infection in the mouth of edentulous patients.

Denture cleaning methods can be performed chemically and/or mechanically. Cleaning by chemical method consists in immersing the denture in solutions with solvent, detergent, antibacterial and antifungal actions (3). A significant feature of the chemical method is the variety of possible active agents. However, these agents present antimicrobial activity against denture biofilm depending on the type of microbial biofilms formed (4) and can cause damages in the acrylic resin denture base (5). The mechanical method is represented by brushing and previous data have shown that brushing with dentifrice is one of the most common methods of denture hygiene (3). This method is inexpensive and simple to use, requiring the adequate combination of brushes and auxiliary agents such as dentifrices (3). The use of adequate brushes and auxiliary agents is essential for the remotion of denture biofilm, control of microorganisms and prevent adverse effects to the material of the denture base (6). The combination of mechanical and chemical methods, which consists in brushing with brush plus dentifrice and immersing the denture in chemical cleansers, is recommended for denture cleansing. However, Paranhos et al. (4) showed that combination method provided results similar to the mechanical method and was more effective than the chemical method for the majority of the tested species of microorganisms. Our clinical experience shows 
that many denture wearers perceive the combination of methods as a complex procedure. Therefore, combination of the mechanical and chemical methods in one step, i.e. mechanical brushing with a dentifrice that has in its composition an antimicrobial agent, can facilitate the cleaning and sanitizing procedures for denture users. New dentifrices for denture hygiene should be developed in order to obtain an ideal relation between biofilm removal and potential antimicrobial $(7,6)$.

Dentifrices have a complex composition. The main components are water, detergents, thickeners, pigments, flavorings and abrasive agents. Antimicrobial substances or other therapeutic agents can also be included. The development of a dentifrice formulation should consist of adequate antimicrobial and surfactants for a more efficient biofilm removal (8). The literature has increasingly focused its attention on the antimicrobial activity of plants and seeds as raw material for manufacturing dentifrices and soaking solutions. Some of the benefits of their use concern their relative safety when compared with synthetic alternatives, offering significant and more affordable therapeutic benefits (9).

One of these plants is Ricinus communis, which is a s plant species typically found in tropical climate areas. The oil extracted from the $R$. communis seeds has a strong surfactant with antimicrobial and anti-inflammatory activities, as well as biocompatibility with periapical tissues (10). This study evaluated the antimicrobial activity of a dentifrice formulated with $R$. communis in different concentrations to be employed in denture hygiene.

\section{Material and Methods}

This study included the commercial dentifrices Colgate (Colgate-Palmolive Division Kolynos Brazil, Osasco, SP, Brazil) and Trihydral (Perland Pharmacos Ltd., Cornelio Procópio, $P R$, Brazil) and Corega Brite (GSK - GlaxoSmithKline, Brazil Ltda, Rio de Janeiro, RJ, Brazil). These dentifrices were chosen in order to cover a wide range of clinical indications, i.e., dentate subjects (Colgate), removable denture cleansing (Corega Brite) or both (Trihydral).

The $R$. communis oil was obtained by a reaction of esterification and it consists of triglycerides containing fatty acids, such as ricinoleic acid, linoleic acid, stearic acid, palmitic acid, dihydroxystearic acid, licosanoic acid and linolenic acid (Chemistry Institute of São Carlos, University of São Paulo, São Carlos, SP, Brazil). The Broth Microdilution method was used to determine the minimum inhibitory concentration (MIC) of $R$. communis necessary for formulation of experimental dentifrice.

The microdilution technique in 96-well plates was performed in duplicate against S. aureus (ATCC 25923), E. coli (ATCC 25922), S. mutans (ATCC 25175), Enterococcus faecalis (ATCC 29212), C. albicans (ATCC 10231) and C. glabrata (ATCC 2001).

A $5 \%$ solution was initially prepared with the dilution of $0.5 \mathrm{~g}$ of $R$. communis in $9.5 \mathrm{~mL}$ of distilled water. This solution was then diluted in Tryptic Soy Broth (Difco, Sparks, $M D, U S A)$ to obtain the initial concentration of $2.5 \%$. Serial two-fold dilutions were added into $100 \mu \mathrm{L}$ volumes of Tryptic Soy Broth in the wells. The procedure resulted in 10 concentrations that varied from 2.5 to $0.0048 \%$. An aliquot of $5 \mu \mathrm{L}$ of standardized microbial inoculum was added to each well of the microplate.

Microbial suspensions were prepared in saline solution from recent cultures $\left(37^{\circ} \mathrm{C}\right.$ for $24 \mathrm{~h}$ ) containing $10^{\circ} \mathrm{CFU} / \mathrm{mL}$ for bacteria and $10^{6} \mathrm{CFU} / \mathrm{mL}$ for yeast, which correspond to an absorbance of 0.08 and 0.1 at $625 \mathrm{~nm}$ wavelength. Next, the suspensions were diluted to $1: 10$ to order to achieve a bacterial inoculum of approximately $10^{7} \mathrm{CFU} / \mathrm{mL}$ and $10^{5} \mathrm{CFU} / \mathrm{mL}$ for yeast. When aliquots of $5 \mu \mathrm{L}$ standardized microbial inoculum were inoculated in the culture medium, the final concentration of each microorganism was of about $10^{5} \mathrm{CFU} / \mathrm{mL}$ for bacteria and $10^{3} \mathrm{CFU} / \mathrm{mL}$ for the yeasts. Aliquots of $50 \mu \mathrm{L}$ of Tryptic Soy Broth added to $50 \mu \mathrm{L}$ of saline and $5 \mu \mathrm{L}$ standardized microbial inoculum served as a positive control and aliquots of $50 \mu \mathrm{L}$ of Tryptic Soy Broth added to $50 \mu \mathrm{L}$ of $R$. communis solution at $5 \%$ served as negative control.

Figure 1 is a flowchart of the aforementioned technique of the microdilution to obtain the MIC of $R$. communis.

The incubation was performed in a moist chamber at $37{ }^{\circ} \mathrm{C}$ for $24 \mathrm{~h}$ and the wells with the culture medium $R$. communis and inocula were examined for the turbidity of the medium, which indicated microbial growth. MIC was the lowest concentration of the product able to inhibit visible microbial growth.

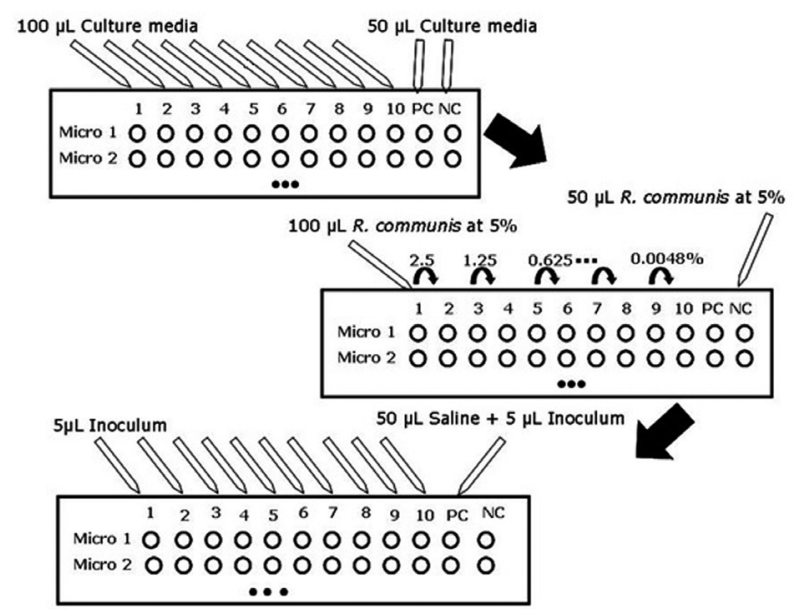

Figure 1. Flowchart of the MIC methodology. PC: Positive Control. NC: Negative Control. 
With the results of the MIC test, four formulations of $R$. communis dentifrice were manipulated with concentrations at 1, 2, 5 and 10\% (Table 1), according to the Good Practices of Pharmaceutical Manufacturing.

During the preparation of the experimental dentifrice, hydroxyethyl cellulose, glycerin, EDTA, saccharin sodium and water were weighed on a digital balance (Ind. and Com GEHAKA Electrical and Electronics Ltd., São Paulo, Brazil, Mod BG400), manually homogenized and kept in a dark container for $24 \mathrm{~h}$ until gel formation. Next, the other components were weighed, gradually added and mixed with the gel in a blender (Model MPDL-6; SEW do Brasil Ltda, São Paulo, Brazil). The $R$. communis was added in sufficient quantity to obtain the desired concentrations of $1,2,5$ or $10 \%$. After obtaining a homogeneous dentifrice, it was dispensed and stored in opaque colored tubes that have a $60 \mathrm{~g}$ capacity.

To evaluate the antimicrobial activity of $R$. communis dentifrices against the microorganisms, the agar welldiffusion double layer technique was used. The experiment was performed in duplicate and the culture mediums used were Sabouraud Dextrose Agar (Difco, Sparks, MD, USA) for C. albicans and C. glabrata and Tryptic Soy Agar (Difco, Sparks, MD, USA) for S. aureus, S. mutans, E. coli and E. faecalis. The culture media were distributed in a Petri dish $(20 \times 10 \mathrm{~mm})$ to obtain the sterile base layer of $12 \mathrm{~mL}$.

Test tubes $(25 \times 150 \mathrm{~mm})$ containing $20 \mathrm{~mL}$ of sterile culture medium were kept in a water bath at $45{ }^{\circ} \mathrm{C}$ after, $200 \mu \mathrm{L}$ of standardized microbial inoculum were inserted in these tubes to obtain 1\% inoculum. The culture medium with the microbial inoculum was homogenized in a tube shaker and transferred to the solidified base layer of the Petri dish, after which the seed layer was formed. Then, 5-mm diameter wells were prepared with sterile straws and a bacteriological needle sterilized with Bunsen burner. The different dentifrices were added to the well and the Petri plates were pre-incubated at room temperature $\left(25^{\circ} \mathrm{C}\right)$ for $2 \mathrm{~h}$ to allow diffusion of the product in the culture medium.

The plates were incubated at $37{ }^{\circ} \mathrm{C}$ for $24 \mathrm{~h}$, and the microorganisms $S$. mutans and $E$. faecalis were incubated under microaerobic conditions. To avoid contact of the water condensation with the culture medium, absorbent paper was placed between the bottom and the cover of the plates. The formation of an inhibition zone around the sample indicated the efficacy of the dentifrice. The diameter of the zones of bacterial growth inhibition produced around the wells was measured (in $\mathrm{mm}$ ) with a rule under reflected light. The measurements were performed three times in each zone to obtain a mean value. Data referring to the antimicrobial activity of the dentifrices were analyzed statistically by analysis of variance and Tukey's post-hoc test $(\alpha=0.05)$.

\section{Results}

The minimum inhibitory concentration (MIC) of $R$. communis was of $0.0781 \%$. Only Escherichia coli was not inhibited with the maximum concentration (Table 2).

The analysis of the antimicrobial activity using the well agar diffusion method revealed statistically significant difference between the dentifrices. Table 3 shows the comparison of the mean diameters $(\mathrm{mm})$ of the zones of bacterial growth inhibition formed around the wells. None of the dentifrices were effective against $E$. coli. Colgate and Trihydral presented similar action against $S$. aureaus and S. mutans. Corega and the experimental dentifrice at $10 \%$ also presented action against S. mutans. Trihydral was the most effective against $E$. faecallis, followed by the experimental dentifrice at $10 \%$ and Colgate, which showed no significant difference between each other $(p>0.05)$. The

Table 1. Experimental dentifrice composition

\begin{tabular}{lcc}
\hline Components & Manufacturer & Function \\
\hline Hydroxyethylcellulose & Union Carbide Corp., Houston, TX, USA & Thickening agent \\
Glycerin & Ely Martins, Ribeirão Preto, SP, Brazil & Humectant \\
EDTA & Dow Chemical Co., Midland, Ml, USA & Chelating agent \\
Saccharin sodium & Labsynth Produtos para Laboratórios Ltda, Diadema, SP, Brazil & Flavoring \\
R. communis gel & Institute of Chemistry of São Carlos (1QSC)/ University & Preservative, antimicrobial \\
Silica (Sident 9) & Evonik Paulo (USP), São Carlos, SP, Brazil & agent, surfactant \\
Silica (Sident 22S) & Evonik Degussa GmbH, Düsseldorf, Germany & Abrasive \\
Titanium dioxide & Minérios Ouro Branco, São Paulo, SP, Brazil & Abrasive \\
Menthol - eucalyptol & Givaudan do Brasil Ltda., São Paulo, SP, Brazil & Pigment (white) \\
Distilled water & - & Flavoring
\end{tabular}


experimental dentifrice showed no antimicrobial activity against Candida spp. in any of the concentrations tested. Against these yeasts, Colgate, Trihydral and Corega showed greater inhibition capacity; Colgate and Trihydral were similar for C. albicans.

\section{Discussion}

This study evaluated the antimicrobial activity of the experimental dentifrice of $R$. communis against microorganisms found in the buccal cavity and complete dentures.

The MIC was performed with the unalloyed $R$. communis to select the dentifrice concentrations. Only E. coli was not inhibited up to the maximum concentration of $2.5 \%$. This microorganism is a Gram negative bacillus transient of the oral cavity that is responsible for the initial adhesion of yeasts on various surfaces (11). E. coli has an outer membrane which covers the thin peptidoglycan layer of the cell wall, which forms a selective barrier to the entry and exit of some substances (12). Additionally, the enzymes in the periplasmatic space are capable of destroying foreign molecules (13), which could explain this result. However,

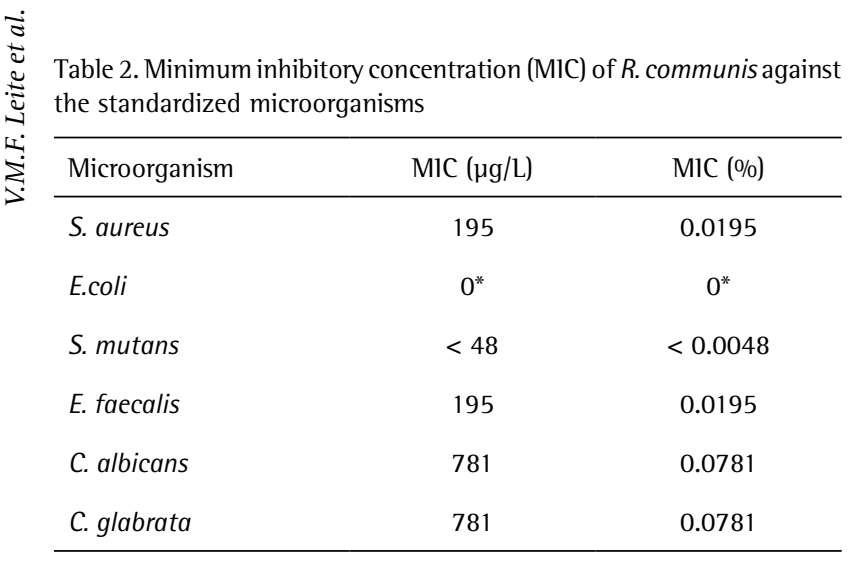

*Initial concentration of $R$. communis analyzed $25.000 \mu \mathrm{g} / \mathrm{L}$ or $2.5 \%$. another study showed that the detergent oil of $R$. communis $10 \%$ was effective against Gram-negative bacteria (10). This result suggests the need for further tests of MIC with $R$. communis at higher concentrations. Increasing the concentration of $R$. communis is a safe procedure, since it is not toxic to the oral tissues (9).

The other microorganisms were inhibited by the concentration of $0.0781 \%$. These results show that $R$. communis is a potential antimicrobial agent and encourage the development of more studies on its antimicrobial activity against denture biofilm microorganisms. The $S$. mutans, is a Gram positive coco with a fundamental role in the initial colonization of denture and natural teeth biofilm, considered the main etiological agent of dental caries (14); S. aureus, Gram positive coco, can cause to opportunistic infections (15) and intestinal infection in immunocompromised patients; the yeast $C$. albicans and $C$. glabrata are the major etiological factors of denture stomatitis and responsible for its maintenance and exacerbation (1); E. faecalis is a Gram-positive coco involved in various diseases of the oral cavity, such as apical periodontitis, recurrent caries and endodontic infections and also the colonization of other sites in the human body, favoring the occurrence of bacterial endocarditis (16).

The action of $R$. communis against these microorganisms can be attributed to its action as "protractors", water catalyzing the hydrolytic reaction by breaking the glycosidic bonds, which are present in the cell wall of the bacteria (17). Although this possibility exists, there are no others studies evaluating the mechanism of antimicrobial action of $R$. communis. Thus, studies need to be conducted since the knowledge of the mechanism of action of antimicrobials is of great importance for adequate and conscious rational use of the product as well as for the elucidation of biochemical phenomena at various levels of the structure of the cells.

The MIC test results enabled choosing to formulate the experimental dentifrices at concentrations of 1 and 2\% with a margin of safety for the most resistant bacteria and, at concentrations of 5 and $10 \%$ to achieve an antimicrobial activity against $E$. coli.

Comparing the antimicrobial activity of the experimental dentifrices and the other commercial dentifrices, it was found that they have no antimicrobial activity against $E$. coli. For other microorganisms, the commercial formulations Colgate and Trihydral, considered with positive controls in this 
study, promote inhibition zone. The antimicrobial action of Trihydral can be attributed to the presence of Chloramine T. This component destroys the cellular material because its reacts with the organic material of microorganisms, causing oxidative reaction and protein hydrolysis, breaking down the cell walls of gram positive bacteria, gram negative bacteria, fungi, viruses, mycobacteria, yeasts, in vegetative form (spores) or not. Panzeri et al. (6) found that a dentifrice containing Chloramine-T was effective against S. mutans, but the Candida spp. counts were not affected by the treatment. The antimicrobial action of Colgate dentifrice can be attributed to the presence of sodium monofluorphosphate in their composition. The fluoride inhibits the enzymatic metabolism of microorganisms in the biofilm, reducing the ability of the microorganisms to decompose carbohydrates (18). The Corega brite, although considered with negative control, also showed action against all microorganisms, exception of $E$. coli. This dentifrice contains sodium bicarbonate in their composition which has an antimicrobial effect over several microorganisms isolated from the oral cavity, including C. albicans (19). In addition, in the presence of water the sodium bicarbonate provides an alkaline $\mathrm{pH}$ to solubilize the fatty acids on the surface, which might hinder bacterial adhesion to the surface (20). However, the effect of sodium bicarbonate on the adherence of these microorganisms should be evaluated since this adhesion can interfere with the biofilm development mechanisms.

The antimicrobial activity results of the experimental dentifrice at 5 and $10 \%$ showed inhibitory activity against $S$. aureaus, $S$, mutans and $E$. faecalis. None of the experimental dentifrices inhibit the growth of Candidaspp. However, a decrease was observed in the concentration of the yeast colonies around the wells corresponding to the experimental dentifrice, suggesting that they presented light antimicrobial activity. Regarding the antimicrobial activity of $R$. communis solutions, the irrigating solution for root canal treatment did not appear to be effective against Gram-negative bacteria (21), while it was effective against Gram-positive bacteria and yeast (9). It is difficult to make comparisons with other studies because there is no available data on the use of $R$. communis associated with dentifrices.

In this study, the $R$. communis gel in its pure form inhibited Candida spp., but it was not effective when used as a component in the experimental dentifrice formulation. Many substances, such as thickening agents, abrasives, humectants, antimicrobial, surfactants, sweeteners and flavorings are present in the composition of dentifrices (22). According to Moran et al. (22), some additives in the formulation of dentifrices can reduce or inhibit the activity of some of their components, but may also increase the substantivity and clinical activity (23). The interaction between different components must be characterized to not impair the action of the formulated product. A complex mixture of the components of a dentifrice should be compatible with the antimicrobial agent, both physically and chemically, so that it is a stable product during storage as well as effective in its application (24). Another factor that could have influenced on the results related to the methodology and techniques used (25). For an antimicrobial agent performs its action by this method (well-agar diffusion), it is necessary that the active ingredient to diffuse through for mean. Ricinus communis presents as the hydrophobic characteristics and the culture medium used for the growth of yeasts, hydrophilic characteristics, their action may have been prejudiced against yeasts.

Further studies with $R$. communis and studies evaluating the interaction between the components are necessary. The components of experimental dentifrices must be fractionated and tested separately.

In the present study, the $R$. communis-based dentifrices presented higher antimicrobial activity against microorganisms commonly found in the oral biofilm of dentate patients, such as Streptococci. These preliminary results suggest that the experimental dentifrices could be better indicated for dentate individuals. However, clinical studies are also necessary to prove the efficacy of $R$. communis. The use of these dentifrice by denture wearers seems to be limited, based on the tested concentrations and methodology used, since they showed no antimicrobial activity against Candida sp., the most common microorganism on denture biofilm. The limitation of this study was the lack of comparison between the antimicrobial agent, $R$. communis, and the antimicrobial agents of commercial dentifrices, due to the different formulation of each dentifrice. However, as the objective was to assess whether the experimental dentifrices presented antimicrobial activity similar to the commercial ones, this study was not impaired. Further research aimed at comparing $R$. communis with antimicrobial agents of different dentifrices and their antimicrobial action on biofilms, will be our next step.

In conclusion, the experimental dentifrices based on R. communis at concentrations of 2, 5 and $10 \%$ presented antimicrobial activity against all microorganisms studied, except for E. coli and Candida spp. The dentifrice at 10\% showed the best antimicrobial activity and presented a similar antimicrobial activity to commercial dentifrices, except against $S$. aureus.

\section{Resumo}

Este estudo avaliou a atividade antimicrobiana de um dentifrício experimental a base de Ricinus communis para higiene de prótese contra 
as seguintes cepas padrão: Staphylococcus aureus, Escherichia coli, Streptococcus mutans, Enterococcus faecalis, Candida albicans e Candida glabrata. 0 ensaio de concentração inibitória mínima foi realizado com $R$. communis em óleo puro a 2,5\% . Apenas a E. coli não foi inibida por $R$. communis, no entanto, a concentração mínima $(0,0781 \%)$ foi eficaz contra os outros microrganismos. A partir destes resultados foram determinadas as concentrações dos dentifricios experimentais: 1, 2, 5 e $10 \%$, as quais foram avaliadas pelo teste de difusão em Agar. Os dentifricios comerciais Colgate, Trihydral e Corega Brite foram testados para fins comparativos. 0 diâmetro dos halos de inibição do crescimento bacteriano, em torno dos poços, foi medido (em $\mathrm{mm}$ ) com uma régua sob uma luz refletida. Os dados foram analisados estatisticamente por meio de análise de variância e teste post-hoc de Tukey $(\alpha=0,05)$. Nem os dentifricios comerciais nem os experimentais foram eficazes contra $E$. coli. Os dentifrícios experimentais contendo $R$. communis a 2, 5 e $10 \%$ apresentaram ação contra S. mutans, $S$. aureaus e $E$. faecallis. Os dentifricios experimentais não mostraram atividade antimicrobiana contra Candida spp e E. coli em nenhuma das concentrações testadas . 0 Trihydral foi o mais eficaz. Comparando os dentifricios experimentais, o produto com $10 \%$ de $R$. communis produziu os maiores halos de inibição do crescimento microbiano e apresentou atividade antimicrobiana.

\section{Acknowledgements}

The authors are grateful to the funding agency FAPESP for the research grant (\#2010/50819-8), to Prof. Denise de Andrade from the Laboratory of Infection Control and Prevention of the Nursing School of Ribeirão Preto, University of São Paulo, to Professors Heitor Panzeri (In memoriam) and Elza Helena Guimarães Lara, from the Clinical Analysis Laboratory HELP and to Professor Gilberto Orivaldo Chierice, from the Institute of Chemistry of São Carlos, University of São Paulo.

\section{References}

1. Figueira MH, Azul A, Pinto E, Fonseca PA, Branco FM, Scully C. Denturerelated stomatitis: identification of a etiological and predisposing factors - a large cohort. J Oral Rehabil 2007;34:448-455.

2. Baena-Monroy $T$, Moreno-Maldonado $V$, Franco-Martínez $F$, Aldape-Barrios B, Quindós G, Sánchez-Vargas LO. Candida albicans, Staphylococcus aureus and Streptococcus mutans colonization in patients wearing dental prosthesis. Med Oral Patol Oral Cir Bucal 2005;10:E27-E29.

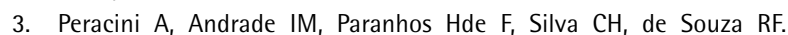
Behaviors and hygiene habits of complete denture wearers. Braz Dent J 2010;21:247-252

4. Paranhos HF, Silva-Lovato $\mathrm{CH}$, de Souza RF, Cruz PC, de Freitas-Pontes $\mathrm{KM}$, Watanabe $\mathrm{E}$ et al. Effect of three methods for cleaning dentures on biofilms formed in vitro on acrylic resin. J Prosthodont 2009;18:42731.

5. Felipucci DNB, Davi LR, Paranhos HFO, Bezzon OL, Silva RF, Pagnano Vo. Effect of different cleansers on the surface of removable partial denture. Braz Dent J 2011;22:392-397.

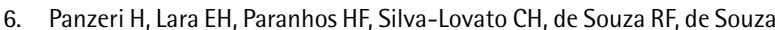
MCG et al. In vitro and clinical evaluation of specific dentifrices for complete denture hygiene. Gerodontology 2009;26:26-33.

7. de Andrade IM, Silva-Lovato $\mathrm{CH}$, de Souza RF, Pisani MX, de Andrade KM, Paranhos HFO. Trial of experimental toothpastes regarding quality for cleaning dentures. Int J Prosthodont 2012;25:157-9.

8. Forward GC, James AH, Barnett $P$, Jackson RJ. Gum health product formulations: what is in them and why? Periodontol 2000 1997:15:3239.

9. Panghal $M$, Kaushal $V$, Yadav JP. In vitro antimicrobial activity of ten medicinal plants against clinical isolates of oral cancer cases. Ann Clin Microbiol Antimicrob 2011;10:21.

10. Ferreira $\mathrm{CM}$, da Silva Rosa OP, Torres $\mathrm{SA}$, Ferreira FB, Bernardinelli $\mathrm{N}$. Activity of endodontic antibacterial agents against selected anaerobic bacteria. Braz Dent J 2002;13:118-122.

11. Samaranayake $L P$, Lamb $A B$, Lamey PJ, MacFarlane TW. Oral carriage of Candida species and coliforms in patients with burning mouth syndrome. J Oral Pathol Med 1989;18:233-235.

12. Black JG. Characteristics of Prokaryotic and Eukaryotic Cells. In Microbilogy: Principles and Explorations. 4 ed. New York: Wiley; 1999. p 75-80.

13. Duffy CF, Power RF. Antioxidant and antimicrobial properties of some Chinese plant extracts. Int J Antimicrob Agents 2001;17:527-529.

14. Thein ZM, Samaranayake YH, Samaranayake LP. Effect of oral bacteria on growth and survival of Candida albicans biofilms. Arch Oral Biol 2006;51:672-680.

15. Tada A, Senpuku H, Motozawa Y, Yoshihara A, Hanada N, Tanzawa H. Association between commensal bacteria and opportunistic pathogens in the dental plaque of elderly individuals. Clin Microbiol Infect 2006;12:776-781.

16. Smyth CJ, Matthews H, Halpenny MK, Brandis H, Colman G. Biotyping, serotyping and phage typing of Streptococcus faecalis isolated from dental plaque in the human mouth. J Med Microbiol 1987;23:45-54.

17. Messetti MA, dos Santos AM, de Angelis DF, Chierice G0, Claro Neto S. Study of a Ricinus communis L. (castor oil) derivative as a biocidal agent and viscosity reducer on Leuconostoc mesenteroides in the sugar and alcohol industries. Arq Inst Biol 2010;77:301-308.

18. Wilkison JB, Moore RJ. Cosmetology of Harry. Madrid: Ediciones Díaz de Santos, S.A. 1990.

19. Cervantes FA, de Sousa G, Paradella TC, Koga-Ito CY, Jorge AOC. Effect of sodium bicarbonate on Candida albicans adherence to thermally activated acrylic resin. Braz Oral Res 2009;23:381-385.

20. Gawande PV, LoVetri K, Yakandawala N, Romeo T, Zhanel GG, Cvitkovitch DG et al. Antibiofilm activity of sodium bicarbonate, sodium metaperiodate and SDS combination against dental unit waterline-associated bacteria and yeast. J Appl Microbiol 2008:105:986-992.

21. Leonardo MR, da Silva LA, Filho MT, Bonifácio KC, Ito IY. In vitro evaluation of the antimicrobial activity of a castor oil-based irrigant. J Endod 2001;27:717-719.

22. Moran J, Addy M, Newcombe RG, Marlow I. A study to assess the plaque inhibitory action of a newly formulated triclosan toothpaste. J Clin Periodontol 2001;28:86-89.

23. Kjaerheim V, Waaler SM, Rölla G. Significance of choice of solvents for the clinical effect of triclosan-containing mouthrinses. Scand J Dent Res 1994;102:202-205.

24. Cummins D, Creeth JE. Delivery of antiplaque agents from dentifrices, gels, and mouthwashes. J Dent Res 1992;71:1439-1449.

25. Alves EG, Vinholis AHC, Casemiro LA, Furtado NAJC, Silva MLA, Cunha $W R$, et al. Comparative study of screening techniques for antibacterial activity evaluation of plant crude extracts and pure compounds. Quim Nova 2008;31:1224-1229. 